\title{
A rare cause of stroke: fail-implanted venous port catheter system - a case report
}

\author{
Mesut Yeniguen ${ }^{1,2+}$, Tobias Braun ${ }^{1,2^{*}+} \mathbb{B}$, Alexander Vlazak ${ }^{1}$, Thomas Umscheid ${ }^{3}$, Martin Juenemann ${ }^{1}$, \\ Tibo Gerriets ${ }^{1,2}$ and Marlene Tschernatsch ${ }^{1}$
}

\begin{abstract}
Background: We present the case of a 75-year-old female with acute embolic cerebral infarction caused by a failimplanted venous port catheter system in the left subclavian artery.

Case presentation: A 75-year-old woman presented to our emergency room after acute onset of a right-sided hemiparesis and dysarthria. Within 2 days after admission, she developed a left-sided hemiparesis, ataxia with concordant gait disturbance and incoordination of the left upper limb. DWI-MRI showed acute multiple infarcts in both cerebral and cerebellar hemispheres. Laboratory examination, 24-h Holter electrocardiography and transthoracic echocardiography provided no pathological findings. Further examination revealed an arterially failimplanted port catheter, placed in the left subclavian artery with its tip overlying the ascending aorta, as the source of cerebral embolism.

Conclusion: This is the first case report of thromboembolic, cerebral infarction due to a misplaced venous port catheter in the subclavian artery, emphasizing the imperative need for a thorough diagnostic workup, when embolism is suspected but cannot be proven at first glance.
\end{abstract}

Keywords: Cerebral infarction, Port catheter system, Thrombemboly, Case report

\section{Background}

Central venous port systems are widely used in modern medicine. The usual complications comprise of local or systemic catheter-related infections, local thromboses with swelling of extremities and malfunction due to mechanical abnormalities. Careful insertion and standardized procedures to ensure correct placement of the port catheter system are vital to avoid periprocedural complications.

\footnotetext{
* Correspondence: tobias.braun@neuro.med.uni-giessen.de

${ }^{+}$Mesut Yeniguen and Tobias Braun contributed equally to this work.

'Department of Neurology, University Hospital Giessen and Marburg, Klinikstrasse 33, 35392 Giessen, Germany

${ }^{2}$ Department of Neurology, Buergerhospital Friedberg, Ockstaedter Strasse 3-5, 61169 Friedberg, Germany

Full list of author information is available at the end of the article
}

We present the first case of a woman with cerebral infarction caused by a failed implanted venous port catheter system residing in the subclavian artery.

\section{Case presentation}

A female in her 70s was admitted to our hospital with the suspected diagnosis of acute ischemic stroke after acute onset of a right-sided hemiparesis. Amongst others, the medical history revealed a short bowel syndrome after ascendojejunostomy with the necessity of diet therapy and parenteral nutritional supplementation via venous port catheter. The percutaneous implantation of the venous port catheter in the left subclavian vein was performed in a different hospital a week before hospital admission. Over recent years, several ports had

(C) The Author(s). 2021 Open Access This article is licensed under a Creative Commons Attribution 4.0 International License, which permits use, sharing, adaptation, distribution and reproduction in any medium or format, as long as you give appropriate credit to the original author(s) and the source, provide a link to the Creative Commons licence, and indicate if changes were made. The images or other third party material in this article are included in the article's Creative Commons licence, unless indicated otherwise in a credit line to the material. If material is not included in the article's Creative Commons licence and your intended use is not permitted by statutory regulation or exceeds the permitted use, you will need to obtain permission directly from the copyright holder. To view a copy of this licence, visit http://creativecommons.org/licenses/by/4.0/ The Creative Commons Public Domain Dedication waiver (http://creativecommons.org/publicdomain/zero/1.0/) applies to the data made available in this article, unless otherwise stated in a credit line to the data. 
already been removed due to catheter-associated complications like lumen occlusion and port-related infections. The port currently inserted had not been used for parenteral nutrition previously.

The patient underwent a standard acute stroke diagnostic workup consisting of non-contrast cranial computed tomography (CT), a 24-h Holter electrocardiography without indications for atrial fibrillation and transthoracic echocardiography revealing normal heart structures. The laboratory results from the patients blood were all within normal paramters, especially the coagulation test (INR, PTT). Extracranial and intracranial duplex sonography indicated marginal atherosclerosis without hemodynamically effective stenoses.

Secondary prophylaxis with antiplatelet (aspirin) and statin medication was initiated. Low-dose enoxaparin was also prescribed to minimise the risk of venous thrombosis. The patient benefited considerably from regularly performed physical therapy, and arm function improved during the first $48 \mathrm{~h}$. Two days after admission, the patient showed an acute onset weakness of the left upper and lower limb, including mild cerebellar signs on the left side.

Brain magnetic resonance imaging (MRI) 2 days post stroke showed multiple small ischemic lesions bilaterally in the cerebellum as well as in subcortical and cortical areas of the cerebral hemispheres, affecting the supplying territory of arteries in the anterior and posterior circulation on both sides (Fig. 1). With regard to the cardioembolic pattern of the infarct lesions (Fig. 1) and until this point - missing cardiac source of emboli, a bubble test by transcranial color-coded duplex sonography (TCCD) was performed, which couldn't determine a right-to-left cardiac shunt.

Before injecting a small amount of saline solution into the port, the patency of the system was verified by cautious aspiration. As the blood returning to the syringe appeared moving pulsatile, an arterially misplaced port catheter was suspected.

The patient was transferred immediately to a vascular surgery department. Conventional angiography showed an arterially placed catheter (Fig. 2) which was later removed during an open surgical exploration. Here, the catheter was found to be entering the left subclavian artery with an organized clot surrounding the catheter tip.

The patient's neurologic status improved missing clinically overt signs of recurrent stroke, and she was able to be transferred to a rehabilitation center after implantation of a new central venous access port device. The patient recovered completely without any neurologic deficit 3 weeks after admission to our hospital.

\section{Discussion and conclusions}

Central venous ports are considered a routine device for long-term administration of chemotherapeutic agents, transfusion blood sampling, repetitive antibiotics and intravenous hydration, or parenteral nutrition, mostly to cancer patients or-as in our case report-chronically ill patients $[1,2]$.

The use of a central venous port was initially described by Niederhuber et al., who reported the first implantation in 1982 via the subclavian vein [3].

A reliable implantation technique and regular maintenance of the venous port systems is indispensable in

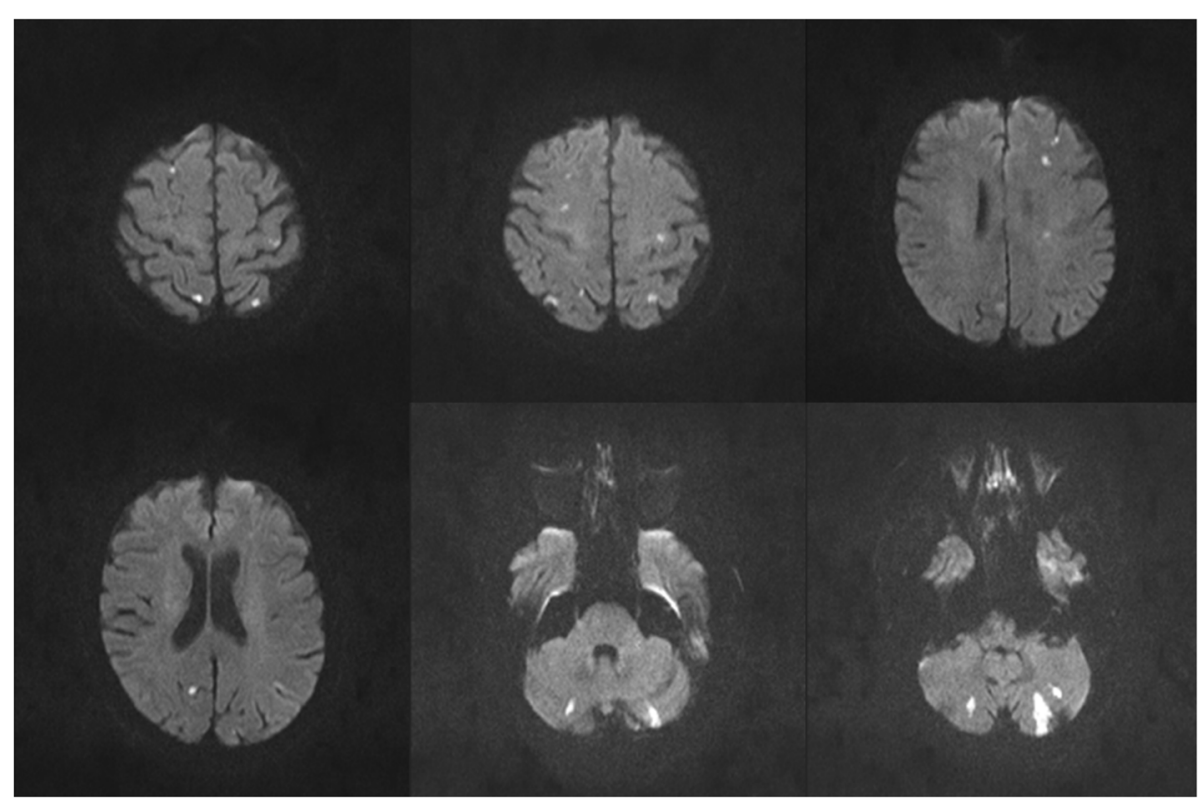

Fig. 1 Axial DWI-MRI displaying hyperintense signals in both hemispheres in the cerebral cortex, subcortex and in the cerebellum 


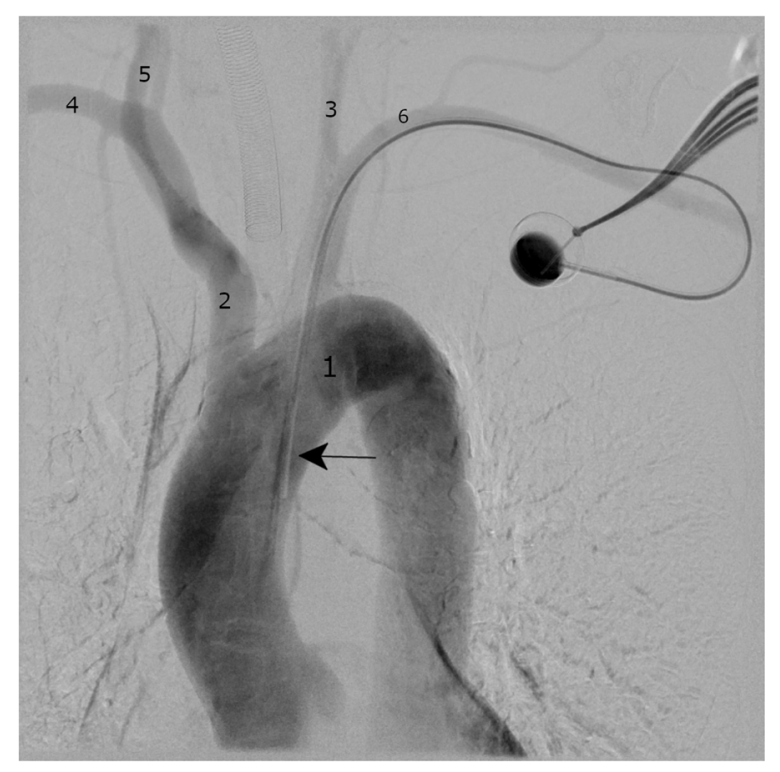

Fig. 2 Intraoperative angiography of the aortic arch via port catheter system allows visualization of the misplaced port catheter and the supra-aortic arteries. Aortic arch (1), brachiocephalic trunk (2), left common carotid artery (3), right subclavian artery (4), right common carotid artery (5), left subclavian artery (6), tip of the catheter (arrow)

order to avoid catheter and port-related complications, such as catheter obstruction, venous thrombosis, infection and mechanical complications. In the literature referring to larger patient cohorts, the indicated complication rate ranges from 10.4 to $15.1 \%[4,5]$. In recent studies, an increased risk for ischemic stroke and cerebral gas embolism after implantation of a central nervous catheter were reported, which is associated with worse functional outcome $[6,7]$.

A broad variety of methods exist to implant a port catheter: Surgeons cut down or percutaneously puncture the forearm and upper-arm peripheral veins, the subclavian, or jugular vein, whereas radiologists perform minimally invasive venography, ultrasound, or fluoroscopy guidance of the subclavian or jugular vein $[2,8]$.

A careful insertion of the catheter system and skilled management should decrease the incidence of complications. The early diagnosis of arterial misplaced catheter can be obtained by the color of blood, the pressure and pulsatile backflow observed through the catheter, blood gas analysis and the postinsertion chest $\mathrm{x}$-ray $[2,4,8-$ 10]. Obviously, the diagnosis of arterial misplacement of the catheter in the present case has been missed and not recognized during the insertion of the catheter, and the further routinely performed chest film following implantation.

Clinical findings and laboratory samples help to identify infectious complications, including local and catheter-related blood stream infections. Venous thrombotic complications usually manifest as arm or facial swelling, cyanosis, venous distension, and superficial venous collateralization. Mechanical complications include catheter malposition, occlusion or fragmentation, port damage and fibrin sheath formation. These complications lead to system malfunction, usually discovered earlier and, in consequence, system explantation and reimplantation may occasionally be required. Further complications, such as infusion pump dysfunction or human error, can also occur and are difficult to distinguish from mechanical complications [2, 9-11].

Such cases will have a rarity value. In current literature, no case has been described wherein an arterially displaced port catheter was left in situ a period of time, causing cerebrovascular events such as embolic cerebral infarction. Cerebrovascular symptoms caused by infusion of parenteral medication and nutrition via venous catheter were described only in a few cases [12].

Neurologic symptoms presented in temporal association with the insertion of a newly placed venous central port catheter might help to ensure the correct diagnosis before irreversible damage occurs. Intermittent embolization of small clots formed on the tip of the catheter following shear-induced platelet aggregation might be the possible pathophysiologic mechanism responsible for focal neurologic symptoms in the presented case. Nowadays, the arterially placed catheter would have probably been detected earlier, as CTangiography is now routinely used in stroke patients, according to national stroke guidelines. This is due to the fact that CT-angiography helps to identify patients with large-vessel occlusion that might benefit from thrombectomy.

This case report highlights the symptoms of embolic cerebral infarction related to an arterially misplaced port catheter and emphasizes the imperative need for a thorough diagnostic workup when embolism is suspected but cannot be proven by standard diagnostic stroke workup.

\section{Take-home points}

To avoid catastrophic complications of misplaced venous port symptoms, the following steps should be taken:

- Ultrasound guidance to localize the anatomic conditions of preferred vein

- Post insertion chest x-ray with critical evaluation

- Blood gas analysis and testing the catheter with about $100 \mathrm{ml}$ of crystalloid solution running via gravity through newly placed catheter

- Reevaluation of catheter conditions in case of neurologic symptoms occurred with initiation of newly inserted catheter and after initiation of infusion. 


\section{Abbreviations}

CT: Computed tomography; DWI-MRI: Diffusion-weighted magnetic resonance imaging; MRI: Magnetic resonance imaging; TCCD: Transcranial color-coded duplex sonography

\section{Acknowledgements}

Not applicable.

\section{Authors' contributions}

$M Y, A V, M T, M J$ and TG treated the patient. TU performed the operation on the patient. MY and TB wrote the manuscript. All authors were involved in the analysis and interpretation of findings. They proved the manuscript und contributed for important intellectual content. All authors contributed to writing and approved the final manuscript.

\section{Funding}

Open Access funding enabled and organized by Projekt DEAL.

\section{Availability of data and materials}

Data sharing is not applicable to this article as no datasets were generated or analysed during the current study.

\section{Declarations}

\section{Ethics approval and consent to participate}

Not applicable.

\section{Consent for publication}

Written informed consent was obtained from the patient for publication of this case report and any accompanying images. A copy of the written consent is available for review by the corresponding author.

\section{Competing interests}

All authors report no competing interests.

\section{Author details}

${ }^{1}$ Department of Neurology, University Hospital Giessen and Marburg, Klinikstrasse 33, 35392 Giessen, Germany. ${ }^{2}$ Department of Neurology, Buergerhospital Friedberg, Ockstaedter Strasse 3-5, 61169 Friedberg, Germany. ${ }^{3}$ HELIOS Klinik für Gefäßmedizin, Emser Straße 29-31, 65307 Bad Schwalbach, Germany.

Received: 22 February 2021 Accepted: 8 April 2021

Published online: 14 April 2021

\section{References}

1. Kock HJ, Pietsch M, Krause U, Wilke H, Eigler FW. Implantable vascular access systems: experience in 1500 patients with totally implanted central venous port systems. World J Surg. 1998;22:12-6. https://doi.org/10.1007/s002 689900342.

2. Walser EM. Venous access ports: indications, implantation technique, followup, and complications. Cardiovasc Intervent Radiol. 2012;35:751-64. https:// doi.org/10.1007/s00270-011-0271-2.

3. Niederhuber JE, Ensminger W, Gyves JW, Liepman M, Doan K, Cozzi E. Totally implanted venous and arterial access system to replace external catheters in cancer treatment. Surgery. 1982;92:706-12.

4. Wildgruber M, Borgmeyer S, Haller B, Jansen H, Gaa J, Kiechle M, et al. Short-term and long-term outcome of radiological-guided insertion of central venous access port devices implanted at the forearm: a retrospective monocenter analysis in 1704 patients. Eur Radiol. 2015;25:60616. https://doi.org/10.1007/s00330-014-3417-1.

5. Klösges L, Meyer C, Boschewitz J, Andersson M, Rudlowski C, Schild HH, et al. Long-term outcome of peripherally implanted venous access ports in the forearm in female Cancer patients. Cardiovasc Intervent Radiol. 2015;38: 657-64. https://doi.org/10.1007/s00270-014-0975-1.

6. Liao P-H, Lai C-Y, Wu C-H, Su Y-C, Wei C-W, Kao C-H. Central venous catheter use increases ischemic stroke risk: a nationwide population-based study. QJM. 2019;112:771-8. https://doi.org/10.1093/qjmed/hcz152.

7. Pinho J, Amorim JM, Araújo JM, Vilaça H, Ribeiro M, Pereira J, et al. Cerebral gas embolism associated with central venous catheter: systematic review. J Neurol Sci. 2016;362:160-4. https://doi.org/10.1016/j.jns.2016.01.043.
8. Gibson F, Bodenham A. Misplaced central venous catheters: applied anatomy and practical management. Br J Anaesth. 2013;110:333-46. https:// doi.org/10.1093/bja/aes497.

9. Teichgräber UKM, Kausche S, Nagel SN, Gebauer B. Outcome analysis in 3,160 implantations of radiologically guided placements of totally implantable central venous port systems. Eur Radiol. 2011;21:1224-32. https://doi.org/10.1007/s00330-010-2045-7.

10. Coady K, Ali M, Sidloff D, Kenningham RR, Ahmed S. A comparison of infections and complications in central venous catheters in adults with solid tumours. J Vasc Access. 2015;16:38-41. https://doi.org/10.5301/jva.5000300.

11. Vardy J, Engelhardt K, Cox K, Jacquet J, McDade A, Boyer M, et al. Longterm outcome of radiological-guided insertion of implanted central venous access port devices (CVAPD) for the delivery of chemotherapy in cancer patients: institutional experience and review of the literature. $\mathrm{Br} J$ Cancer. 2004;91:1045-9. https://doi.org/10.1038/s.bjc.6602082.

12. Shah PM, Leong B, Babu SC, Goyal AM, Mateo RB. Cerebrovascular events associated with infusion through arterially malpositioned triple-lumen catheter: report of three cases and review of literature. Cardiol Rev. 2005;13: 304-8. https://doi.org/10.1097/01.crd.0000160307.89405.30.

\section{Publisher's Note}

Springer Nature remains neutral with regard to jurisdictional claims in published maps and institutional affiliations.

\section{Ready to submit your research? Choose BMC and benefit from:}

- fast, convenient online submission

- thorough peer review by experienced researchers in your field

- rapid publication on acceptance

- support for research data, including large and complex data types

- gold Open Access which fosters wider collaboration and increased citations

- maximum visibility for your research: over $100 \mathrm{M}$ website views per year

At BMC, research is always in progress.

Learn more biomedcentral.com/submissions 